\title{
MONITORAMENTO AMBIENTAL DO GLIFOSATO E DO SEU METABÓLITO (ÁCIDO AMINOMETILFOSFÔNICO) NA ÁGUA DE LAVOURA DE ARROZ IRRIGADO
}

\author{
MARIA LAURA TURINO MATTOS * \\ MARIA DO CARMO RUARO PERALBA * \\ SILVIO L. P. DIAS \\ FÁBIO PRATA **** \\ LARISSA CAMARGO *****
}

\begin{abstract}
Monitorou-se a presença do herbicida Glifosato e do seu metabólito, ácido aminometilfosfônico (AMPA), em amostras de águas coletadas em área orizícola, submetida a plantio direto. Níveis de Glifosato em concentrações acima do limite máximo permitido $(7,0 \mu \mathrm{g} / \mathrm{L})$ pela Agência de Proteção Ambiental dos Estados Unidos (Environmental Protection Agency) foram detectados. A presença do metabólito AMPA, nas águas dos canais de irrigação, foi detectada até 120 dias após a aplicação (DAA). Pode-se dizer que determinado nível de segurança será alcançado nas águas de lançamento da granja para o Arroio Bretanhas, 120 DAA da formulação de Glifosato. Como não foi observada deserção do Glifosato em GLEYSSOLO HÁPLICO Ta Eutrófico pode-se inferir que a concentração do mesmo permaneceu como resíduo ligado. Assim, a dissipação do herbicida nesse solo pode ser reflexo, entre outros fatores, da formação de resíduo ligado, determinando desta forma o seu destino e/ou comportamento no ambiente.
\end{abstract}

PALAVRAS-CHAVE: GLIFOSATO-RESÍDUOS; ÁGUA; GRÃOS.

\section{INTRODUÇÃO}

A determinação do comportamento ambiental de pesticidas e de seus metabólitos, no ecossistema de arroz irrigado, deve integrar os processos de registro das moléculas químicas. Um componente crítico

\footnotetext{
* $\quad$ Eng ${ }^{\circ}$. Agr ${ }^{\circ}$., Dra., Pesquisadora, Embrapa Clima Temperado, Pelotas, RS (email: mattos@cpact.embrapa.br).

** Química, Dra., Professora, Instituto de Química, Universidade Federal do Rio Grande do Sul (UFRGS), Porto Alegre, RS.

*** Químico, Doutorando, Instituto de Química, UFRGS, RS.

**** Eng ${ }^{\circ}$. Agro ${ }^{\circ}$., Doutorando, Escola Superior de Agricultura Luiz de Queiroz, Universidade de São Paulo, Piracicaba, SP.

Estudante de Farmácia, UFRGS, Bolsista de Iniciação Científica da FAPERGS, Porto Alegre, RS.
} 
dessa determinação é a avaliação do potencial do pesticida e de seus metabólitos contaminarem as fontes de águas superficiais e subterrâneas. Os recursos hídricos são fundamentais para o funcionamento dos ecossistemas aquáticos, sendo fontes para o fornecimento de água potável. Dados provenientes de estudos de monitoramento sobre a ocorrência de pesticidas em águas superficiais, no Rio Grande do Sul, ainda são escassos.

A lavoura orizícola, no Rio Grande do Sul, com área de 952.539 ha (IRGA, 2000), utiliza grande número de pesticidas, especialmente os herbicidas. Consta na recomendação oficial (EMBRAPA, 1999) a indicação de 27 produtos químicos de diferentes classes toxicológicas para essa finalidade. Dentre esses produtos destaca-se o Glifosato, nome comum do $\mathrm{N}$-(fosfometil) glicina, herbicida pós-emergente de ação total, não seletivo, utilizado em lavouras de arroz irrigado cultivadas em plantio direto. A formulação (concentrado solúvel) apresenta $360 \mathrm{~g} \mathrm{~L}^{-1}$ de Glifosato (ingrediente ativo), representando $41 \%$ da composição porcentual da formulação comercial, enquanto que os outros $59 \%$ incluem o composto polietoxietilenoamina (POEA), o sal de isopropilamina e outros ingredientes. A dose letal (DL50), baseada na alimentação oral de ratos machos, é de $4320 \mathrm{mg} \mathrm{kg}^{-1}$, enquanto a DL50 dérmica, para coelhos, é de $7940 \mathrm{mg} \mathrm{kg}^{-1}$, sendo caracterizado como composto de baixa toxicidade (MONSANTO, 1980). A exposição mais freqüente das pessoas ao Glifosato ocorre pelo trabalho (pessoas que usam este herbicida nas suas atividades), ingestão de alimentos contaminados, exposição causada pela deriva e contato com o solo ou águas de consumo e recreação (COX, 1995).

No solo, o Glifosato é fortemente adsorvido pelos colóides de argila e húmus, tendo persistência média de 30 a 90 dias, dependendo do teor de matéria orgânica e da atividade microbiana, baixa lixiviação e insignificantes perdas por fotodecomposição e/ou volatilização (MONSANTO, 1980). GLASS (1987) cita que o Glifosato é complexado pelos cátions liberados das argilas, via reação de troca de cátions com a solução de prótons, formando complexos de Glifosato. Os microrganismos são os principais responsáveis pela degradação do Glifosato. Aproximadamente $50 \%$ da molécula original é metabolizada em 28 dias, chegando a $90 \%$ em 90 dias (RODRIGUES e ALMEIDA, 1995). Por essa razão, vários metabólitos ou produtos da degradação do herbicida têm sido identificados. O ácido aminometilfosfônico (AMPA) é o principal produto da sua degradação no solo, sendo formado pela ação microbiana. Ambos são altamente solúveis em água e podem entrar em ambientes aquáticos, quando o Glifosato é usado diretamente como herbicida para o controle de plantas aquáticas e banco de invasoras ou pelo escorrimento superficial de áreas em que foi aplicado (MOGADATI et al., 1996). 
Microrganismos indígenas (cepas bacterianas MG1, MG2 e MG3, e os fungos Nigrospora sphaerica, Cochliobolus heterostrophus, Fusarium anthophilum e Micelia sterilia) isolados de lavouras de arroz irrigado cultivadas em plantio direto foram capazes de degradar o herbicida Glifosato, tendo-o como única fonte de carbono (MATTOS et al., 2001a,b).

$\mathrm{O}$ estudo do comportamento ambiental do Glifosato e de seus metabólitos requer o desenvolvimento de método analítico adequado aos objetivos a serem atingidos. A cromatografia líquida de alta resolução (High-Performance Liquid Chromatographic $=$ HPLC) constitui método de quantificação largamente utilizado na análise desse princípio ativo, tendo inclusive sido adotada como padrão pela Agência de Proteção Ambiental Americana (Environmental Protection Agency). O caráter iônico e a solubilidade em água do Glifosato e do AMPA tornam a análise por cromatografia a líquido vantajosa sobre a cromatografia a gás.

O objetivo desta pesquisa foi monitorar a presença do herbicida Glifosato e do seu metabólito AMPA em amostras de águas, coletadas em área orizícola com lavouras de plantio direto, de modo a avaliar o impacto do uso desse herbicida sobre os recursos hídricos, especialmente, no Arroio Bretanhas e na Lagoa Mirim.

\section{MATERIAL E MÉTODOS}

Amostras foram coletadas em lâminas de água, em lavouras de arroz irrigado, canais (de irrigação e drenagem), açudes e levantes de uma granja orizícola, no Litoral Sul do Rio Grande do Sul. Utilizou-se o método recomendado pela BIO-RAD (1990), com a finalidade de determinar quanti e qualitativamente o herbicida Glifosato e seu metabólito (AMPA). O monitoramento da qualidade da água foi realizado a partir da obtenção de amostras, diretamente, do levante de entrada de água da Lagoa Mirim para o canal-mestre da granja até o ponto de lançamento para o Arroio Bretanhas. O monitoramento foi realizado nas safras de 1999/2000 e 2000/ 2001 , sendo coletadas amostras compostas de águas superficiais em fevereiro de 1999 e no período compreendido entre dezembro de 1999 e março de 2000, totalizando 39 pontos amostrais.

As amostras de água foram submetidas ao procedimento de clean-up para extração de Glifosato e AMPA, utilizando-se resina complexante Chelex na forma férrica e em seguida aplicadas em resina de troca aniônica com eluição dos compostos com $\mathrm{HCl} 6 \mathrm{M}$. O eluato, ácido resultante, foi concentrado em rotavapor e, após diluição, analisado em Cromatógrafo a Líquido de Alta Performance (HPLC) Shimadzu, série 
LC-10A, equipado com três módulos para bombeamento isocrático com fluxo constante, acoplado a forno Shimadzu CTO-10A para aquecimento da coluna analítica mantida em temperatura constante de $50^{\circ} \mathrm{C}$. Usou-se coluna de guarda, contendo como enchimento $\mathrm{C}_{18}$ Corasil 37-55 $\mu \mathrm{m}$, sistema de derivatização pós-coluna com duas serpentinas de reação Shimadzu CRB-6A, mantidas em temperatura constante de $38^{\circ} \mathrm{C}$ e detector de Fluorescência, RF-10Axl, com comprimento de onda de excitação e emissão em 350 e 440 nm, respectivamente.

Os dados foram coletados e analisados utilizando-se módulo de interface $\mathrm{CBM}-10^{\mathrm{A}}$, que comunica as unidades do cromatógrafo com sistema de trabalho CLASS-LC10 Shimadzu. As amostras foram injetadas via válvula Rheodyne com loop de $50 \mu \mathrm{L}, \mathrm{CA}$, USA. Foi utilizada coluna Aminex, de troca catiônica [250 mm x 4,6 mm $(9,0 \mu \mathrm{m})]$ na forma $\mathrm{K}^{+}$ BioRad HRLC. A velocidade de fluxo, para a fase móvel, na coluna analítica foi de $0,5 \mathrm{~mL} \mathrm{~min}^{-1}$ e os fluxos para as soluções oxidativas e do OPAMERC no sistema de pós-reação de $0,4 \mathrm{~mL} \mathrm{~min}^{-1}$.

No procedimento de análise de Glifosato e AMPA residuais foi utilizada amostra de água de $100 \mathrm{~mL}$, acidificada até $\mathrm{pH} 2,0 \pm 0,4 \mathrm{com}$ $\mathrm{HCl} 6 \mathrm{M}$, e, então, filtrada em membrana de filtro de vidro para posterior aplicação em resina Chelex 100.

Amostras de GLEYSSOLO HÁPLICO Ta Eutrófico (EMBRAPA, 1999) também foram coletadas, na profundidade de $0-20 \mathrm{~cm}$, em lavoura de arroz irrigado, cultivada em plantio direto. Determinou-se a capacidade de adsorção do Glifosato nessa classe de solo, avaliando a sua capacidade para dessorção e, conseqüentemente, o risco potencial de contaminação do solo e da água. Após a coleta, as amostras de solo foram secas ao ar e passadas em peneira com malha de $2,0 \mathrm{~mm}$. Para a realização dos testes de sorção foram utilizadas cinco soluções com diferentes concentrações de Glifosato: 0,$42 ; 0,84 ; 1,68 ; 3,36$ e $6,72 \mathrm{mg} \mathrm{L}^{-1}$. A concentração de $0,84 \mathrm{mg} \mathrm{L}^{-1}$, na relação solo:solução empregada (2:10) correspondeu à dose máxima recomendada no campo. As soluções foram preparadas em $\mathrm{CaCl}_{2}$ 0,01 $\mathrm{mol} \mathrm{L}^{-1}$, misturando-se o produto técnico (pureza $=96 \%)$ com o seu isótopo radioativo $\left({ }^{14} \mathrm{C}\right.$-fosfonometil, pureza $=99 \% \mathrm{e}$ atividade específica $\left.=5,155 \mathrm{MBq} \mathrm{mg}^{-1}\right)$. Nas diferentes soluções, a concentração radioativa correspondeu a $0,233 \mathrm{kBq} \mathrm{mL}^{-1}$. Amostras de $2,0 \mathrm{~g}$ de solo e alíquotas de $10 \mathrm{~mL}$ de solução foram acondicionadas em tubos de centrífuga ( $50 \mathrm{~mL}$ ), em triplicata, os quais foram horizontalmente agitados $(200 \mathrm{rpm})$ durante 6 horas a $25 \pm 2^{\circ} \mathrm{C}$. Subseqüentemente, 0 conteúdo suspenso nos tubos foi centrifugado (3000 rpm, por $10 \mathrm{~min}$ ), retirando-se alíquota de $1 \mathrm{~mL}$ do sobrenadante para determinar a concentração de Glifosato na solução de equilíbrio (Ce) por espectrometria de cintilação líquida. Para tal, assumiu-se que toda a radioatividade estaria 
na forma de Glifosato. A quantidade sorvida ao solo foi determinada pela diferença entre a concentração inicial e a concentração de equilíbrio.

Para o estudo de dessorção, os sobrenadantes dos tubos de centrífuga foram descartados e alíquotas de $10 \mathrm{~mL}$ de solução de $\mathrm{CaCl}_{2}$ $0,01 \mathrm{~mol} \mathrm{~L}^{-1}$ adicionadas somente à solução com concentração de $0,84 \mathrm{mg} \mathrm{L}^{-1}$. Posteriormente, os tubos foram agitados, centrifugados e 0 novo sobrenadante foi descartado da mesma forma que no teste de sorção. Esse procedimento foi repetido por mais três vezes, após o qual as amostras de solo foram secas ao ar, homogeneizadas e retiradas subamostras $(0,4 \mathrm{~g})$ para determinar, por combustão em oxidador biológico, a radioatividade sorvida ao solo. Isto permitiu o fechamento do balanço de massa radioativa.

Para o cálculo das constantes de sorção e dessorção foi utilizado o modelo matemático linearizado de Freundlich (Equação 1).

$$
\log S=\log K_{f}+N \log C_{e}
$$

na qual:

$\mathrm{S}=$ concentração de Glifosato sorvido $\left(\mu \mathrm{g} \mathrm{g}^{-1}\right)$;

$\mathrm{C} e=$ concentração de Glifosato na solução de equilíbrio $\left(\mu \mathrm{g} \mathrm{mL}^{-1}\right)$;

$\mathrm{K} \mathrm{f}=$ constante de sorção ou dessorção de Freundlich; e

$\mathrm{N}=$ grau de linearidade da isoterma.

\section{RESULTADOS E DISCUSSÃO}

A precisão instrumental foi verificada por meio da medição seqüencial de dez injeções repetitivas dos analitos Glifosato e AMPA, em concentrações de $100 \mu \mathrm{g} \mathrm{L}^{-1}$. O desvio padrão (\%RSD), calculado para as áreas dos picos do Glifosato e do AMPA foram $<10 \%$, o que garantiu precisão.

Nas Figuras 1 e 2 são apresentadas as curvas de calibração para os analitos Glifosato e AMPA, respectivamente, calculadas pelo método dos mínimos quadrados. O procedimento adotado consistiu na elaboração de curva de calibração de cada lote de amostras analisadas.

O estabelecimento do limite de detecção (LD) do Glifosato foi de $10,0 \mathrm{ppb}$ e do AMPA de 5,0 ppb com atenuação zero. Abaixo desses valores de concentração, os analitos foram considerados como não detectados (ND). 
FIGURA 1 - CURVA DE CALIBRAÇÃO UTILIZADA PARA OBTENÇÃO DAS CONCENTRAÇÕES DE GLIFOSATO EM AMOSTRAS DE ÁGUA DE LAVOURA DE ARROZ(RS)

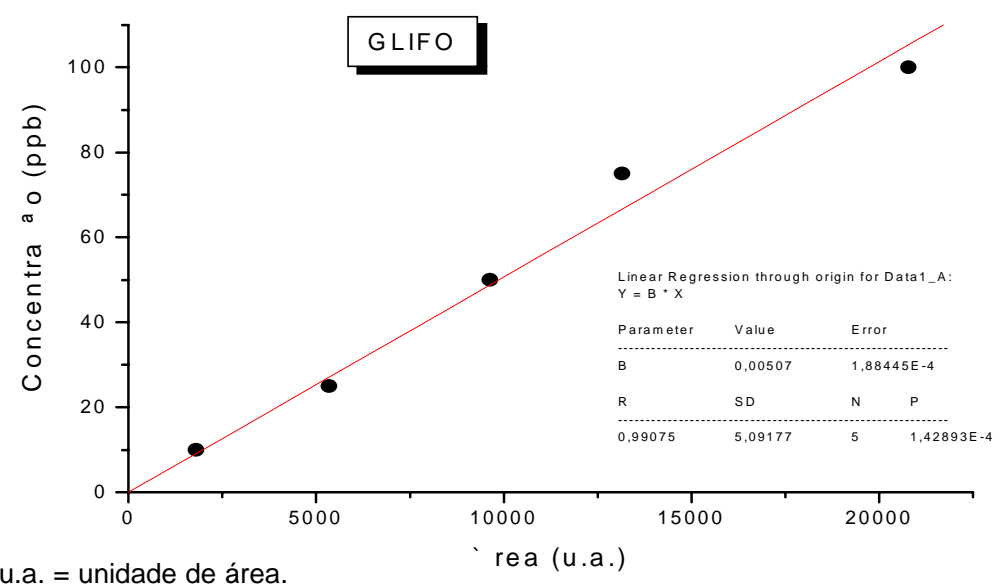

FIGURA 2 - CURVA DE CALIBRAÇÃO UTILIZADA PARA OBTENÇÃO DAS CONCENTRAÇÕ̃ES DE AMPA NAS AMOSTRAS DE ÁGUA DE LAVOURA DE ARROZ(RS)

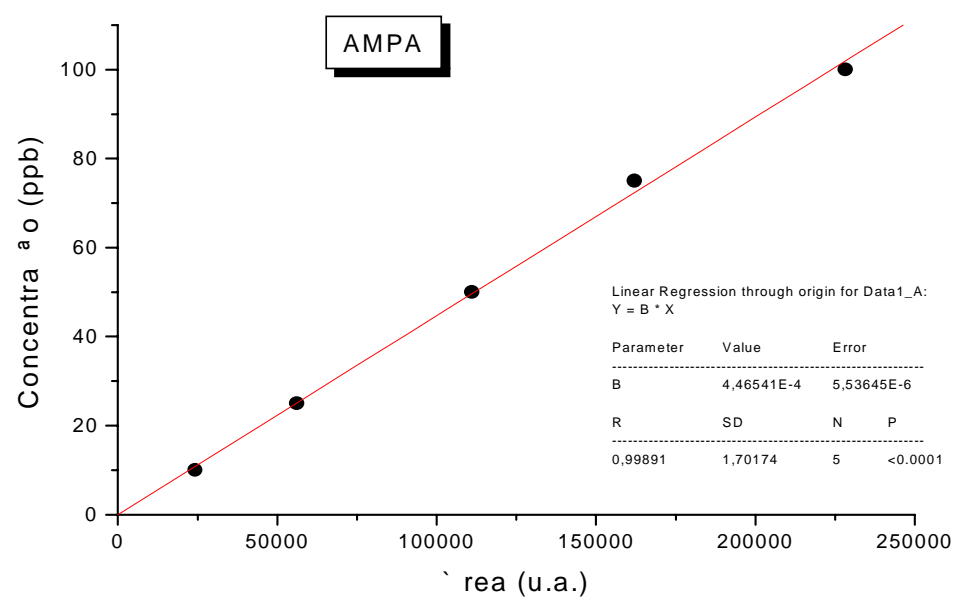

u.a. = unidade de área. 
Os percentuais de recuperação dos analítos Glifosato e AMPA, em amostras de água foram de 79,1 $\pm 1,2$ e 81,7 $\pm 2,1$, respectivamente. A metodologia cromatográfica desenvolvida mostrou-se eficiente para a extração do Glifosato e do AMPA em amostras de água (Figura 3).

\section{FIGURA 3 - CROMATOGRAMA DE GLIFOSATO E SEU METABÓLITO PRINCIPAL AMPA}

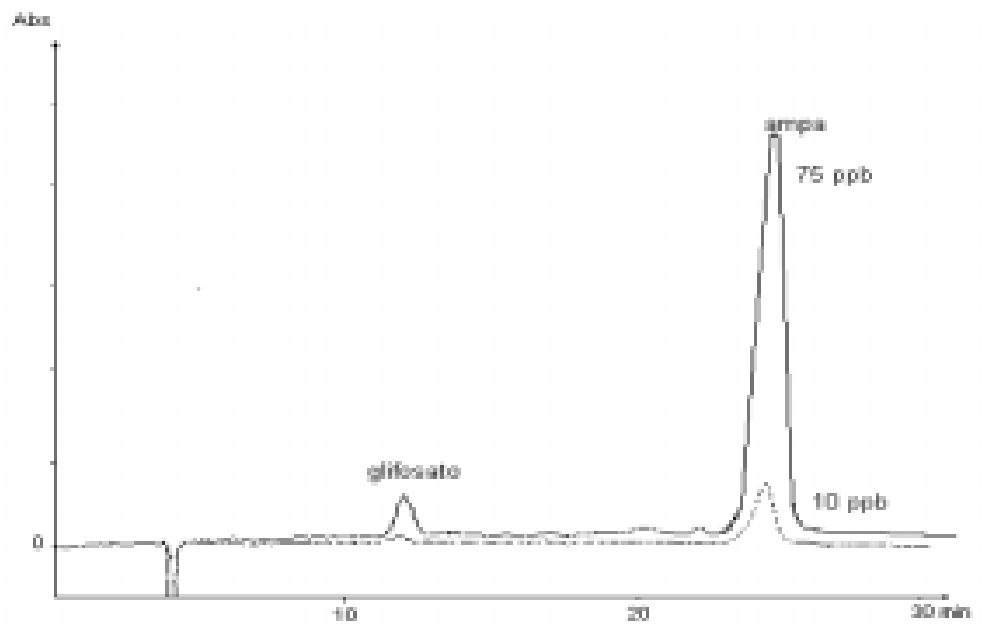

Na Tabela 1 pode-se observar os valores quantificados de Glifosato e de AMPA em alguns pontos amostrais. Após a aplicação do herbicida, ocorrida em novembro de 1999, foi detectada a sua presença em amostras de água em três pontos distintos da granja orizícola, ou seja, na lâmina de água da lavoura de arroz aos 30 dias após a aplicação (DAA), no canal-mestre de entrada de água da Lagoa Mirim (aos 90 DAA) e na saída para o Arroio Bretanhas (aos 90 DAA). A presença de AMPA, na lâmina de água de lavoura de arroz, também foi verificada aos 30 e 90 DAA. Foram encontrados resíduos de AMPA até 120 DAA, nos canais de irrigação e drenagem da granja, variando de 5,0 - 14,50 $\mu \mathrm{g} \mathrm{L}^{-1}$. Resíduos de AMPA foram detectados, nas águas de lançamento para o Arroio Bretanhas, 60 dias após aplicação do herbicida. No açude localizado no interior da granja foram encontrados resíduos de AMPA aos 120 DAA. Não foram detectados resíduos do Glifosato e de AMPA na água destinada a recreação, localizada em um canal da granja. 


\section{TABELA 1 - CONCENTRAÇÕES DE GLIFOSATO E AMPA EM AMOSTRAS DE ÁGUAS COLETADAS EM GRANJA ORIZÍCOLA (RS)}

\begin{tabular}{|c|c|c|c|}
\hline Pontos de Coleta & Glifosato $\left(\mu \mathrm{g} \mathrm{L}^{-1}\right)$ & AMPA $\left(\mu \mathrm{gL}^{-1}\right)$ & Data de Coleta \\
\hline Levante Lagoa Mirim-entrada de Agua & ND & ND & $23 / 02 / 99$ \\
\hline Canal de drenagem-BN & ND & $6,1 \pm 0,8^{*}$ & 23/02/99 \\
\hline Canal de esgoto-BN & ND & ND & 23/02/99 \\
\hline Canal de esgoto & ND & $7,4 \pm 1,2$ & 23/02/99 \\
\hline Levante Emergente-entrada de Agua de retorno & ND & $13,8 \pm 0,4$ & 23/02/99 \\
\hline Canal Emergente & ND & $14,0 \pm 1,5$ & 23/02/99 \\
\hline L mina de Fgua de lavoura de arroz-ET & ND & ND & 23/02/99 \\
\hline L mina de Fgua de lavoura de arroz-ET & ND & ND & 23/02/99 \\
\hline L mina de Agua de lavoura de arroz-VM & ND & ND & 23/02/99 \\
\hline L mina de Agua de lavoura de arroz-FG & ND & ND & $23 / 02 / 99$ \\
\hline Levante Costa-entrada de Agua da Lagoa Mirim & ND & ND & 23/02/99 \\
\hline A ude nos fundos da sede & ND & ND & 23/02/99 \\
\hline Canal com Agua para recrea $\stackrel{a}{0} 0$ & ND & ND & 23/02/99 \\
\hline Levante Lagoa Mirim-entrada de Agua & ND & $9,6 \pm 1,2$ & 17/12/99 \\
\hline Canal mestre de entrada de Ægua da Lagoa Mirim & ND & $14,5 \pm 3,5$ & 17/12/99 \\
\hline L mina de Agua de lavoura de arroz irrigado-BN & $144,00 \pm 2,3$ & $113,6 \pm 4,3$ & 17/12/99 \\
\hline Canal de esgoto-BN & ND & $5,9 \pm 0,7$ & $17 / 12 / 99$ \\
\hline Levante Lagoa Mirim-entrada de Agua & ND & ND & $26 / 01 / 00$ \\
\hline Canal mestre de entrada de Agua da Lagoa Mirim & ND & ND & $26 / 01 / 00$ \\
\hline L mina de Agua de lavoura de arroz irrigado-BN & ND & ND & $26 / 01 / 00$ \\
\hline Canal de Esgoto-BN & ND & $9,2 \pm 1,1$ & $26 / 01 / 00$ \\
\hline Levante Arroio Bretanhas-entrada de Agua & ND & ND & $26 / 01 / 00$ \\
\hline Levante Emergente-entrada de Agua de retorno & ND & $14,0 \pm 0,1$ & $26 / 01 / 00$ \\
\hline Sa da de Agua para o Arroio Bretanhas & ND & $13,1 \pm 0,8$ & $26 / 01 / 00$ \\
\hline A ude nos fundos da sede & ND & ND & $26 / 01 / 00$ \\
\hline Levante Lagoa Mirim-entrada de Agua & ND & ND & $24 / 02 / 00$ \\
\hline Canal mestre de entrada de Fgua da Lagoa Mirim & 14,4 & ND & $24 / 02 / 00$ \\
\hline L mina de Agua de lavoura de arroz irrigado-BN & ND & 12,0 & $24 / 02 / 00$ \\
\hline Canal de esgoto-BN & ND & ND & $24 / 02 / 00$ \\
\hline Levante Emergente-entrada de Agua de retorno & ND & $14,0 \pm 0,1$ & $24 / 02 / 00$ \\
\hline Levante Arroio Bretanhas-entrada de Agua & ND & ND & $24 / 02 / 00$ \\
\hline Levante Arroio Bretanhas-sa da de Agua & ND & 12,0 & $24 / 02 / 00$ \\
\hline Levante Arroio Bretanhas-sa da de Ağua & 13,0 & 11,0 & $24 / 02 / 00$ \\
\hline A ude nos fundos da sede & ND & ND & $24 / 02 / 00$ \\
\hline Canal de esgoto para o Arroio Bretanhas & ND & 11,0 & $30 / 03 / 00$ \\
\hline Canal mestre-BN & ND & 5,0 & $30 / 03 / 00$ \\
\hline Canal de esgoto-BN & ND & ND & $30 / 03 / 00$ \\
\hline Levante Costa-canal & ND & ND & $30 / 03 / 00$ \\
\hline A ude nos fundos da sede & ND & 13,0 & $30 / 03 / 00$ \\
\hline
\end{tabular}

$\mathrm{ND}=$ não detectado; $\mathrm{BN}$ = barra negra; $\mathrm{ET}$ = estancinha; $\mathrm{VM}=$ vimes; $\mathrm{FG}$ = figueirinha

* Média de duas repetições \pm desvio padrão.

Os resultados do estudo de adsorção do Glifosato demonstraram que toda a concentração do herbicida aplicada ao solo foi sorvida. Os valores de $\mathrm{K}_{\mathrm{f}-\mathrm{sor}}$ (extremamente elevados) sugeriram elevada energia de ligação. Já os valores de $\mathrm{N}$ e $\mathrm{K}$-sor podem ser considerados como $\mathrm{Kg}$, i.e., parâmetro adequado para expressar a sorção do Glifosato. Os dados 
alimentaram eficientemente o modelo de Freundlich $\left(R^{2}=0,99\right)$ não se observando dessorção (liberação das camadas iônicas ou moleculares presas à superfície para a solução do solo) do Glifosato. PRATA et al. (2001) também observaram a formação de resíduo ligado do Glifosato em solo cultivado, em plantio direto, durante 23 anos. Como o Glifosato é uma molécula hidrofílica, o $\mathrm{CaCl}_{2}$ utilizado para a dessorção pode ser aceito como extrator para a mesma no solo. Assim, a quantidade dessorvida de Glifosato pode ser considerada como extraída.

\section{CONCLUSÃO}

Níveis de Glifosato foram detectados na lâmina de água da lavoura de arroz, no canal mestre de entrada de água da Lagoa Mirim e na saída do Levante Arroio Bretanhas, em concentrações acima do limite máximo permitido $\left(7,0 \mu \mathrm{g} \mathrm{L}^{-1}\right)$ pela Agência de Proteção Ambiental dos Estados Unidos. Como foi detectada a presença do metabólito AMPA nas águas dos canais da granja de arroz, até 120 DAA, pode-se concluir que determinado nível de segurança será alcançado 120 dias após a aplicação da formulação de Glifosato nas águas de lançamento da granja para o Arroio Bretanhas.

Como não foi observada dessorção do Glifosato pode-se inferir que a concentração presente em GLEYSSOLO HÁPLICO Ta Eutrófico (após determinado tempo de equilíbrio químico) permaneceu como resíduo ligado. A dissipação do herbicida nesse solo, no plantio direto de arroz irrigado, pode ser reflexo, entre outros fatores, da formação de resíduo ligado, determinando, desta forma, o destino e/ou comportamento do herbicida no ambiente.

\section{Abstract}

ENVIRONMENTAL MONITORING OF GLYPHOSATE AND ITS METABOLITE (AMINOMETHYLPHOSPHONIC ACID) IN TILLAGE WATER OF IRRIGABLE RICE Monitor the presence of the herbicide glyphosate and its metabolite, aminomethylphosphonic acid (AMPA), in samples of water collected in orizicole area, subject to direct plantation, was the objective of this study. Levels of glyphosate above the maximum permitted concentration limit $(7.0 \mu \mathrm{g} / \mathrm{L})$ were detected by the United States Environmental Protection Agency (EPA). The presence of the metabolite AMPA in irrigation channel water was detected up to 120 days after application (DAA). It can be deduced that a certain level of safety will be reached 120 DAA from formulation of glyphosate, for water from the Arroio Bretanhas farm. Since the desertion of glyphosate in a Gleyssolo Háplico Ta Eutrophic was not observed, it can be judged that the concentration of it remained as bonded residue. Thus, the dissipation of this herbicide in this soil can be a reflex of, among other factors, the formation of bonded residue, determining, in this manner, its destiny and/or behavior in the environment.

KEY WORDS: GLYPHOSATE-RESIDUES; WATER; GRAINS. 


\section{REFERÊNCIAS}

1 BIO-RAD. Glyphosate analysis. California, 1990. 4 p. (Bulletin, n. 1591).

2 COX, C. Glyphosate. Part 2- human exposure and ecological effects. Journal of Pesticide Reform, v. 15, n. 4, p. 14-20, 1995.

3 EMBRAPA. Centro Nacional de Pesquisa de Solos. Sistema brasileiro de classificação de solos. Brasília: Embrapa/Produção de Informação; Rio de Janeiro: Embrapa Solos, 1999. 412 p.

4 EMBRAPA. Embrapa Clima Temperado. Arroz irrigado: recomendações técnicas da pesquisa para o Sul do Brasil. Pelotas: IRGA/EPAGRI, 1999. 124 p. (Documento, 57).

5 GLASS, R.L. Adsorption of glyphosate by soils and clay minerals. J. Agric. Food Chem., Easton, v.35, p. 497-500, 1997.

6 IRGA. Instituto Rio Grandense do Arroz. Informativo, Porto Alegre, v.8, n.4, 2000. 4 p.

7 MATTOS, M.L.T.; PERALBA, M.C.R.; CASTRO, L.A.S.; SANTOS, F.O. Biodegradation of glyfosate by indigenous microorganisms isolated in paddy rice soil. In: FOURTH LATIN AMERICAN BIODETERIORATION AND BIODEGRADATION SYMPOSIUM, 4, 2001 , Buenos Aires. Resumos... Buenos Aires: CITEFA, 2001a. p. 42.

8 MATTOS, M.L.T.; MACHADO, M.I.; SANTOS, F.O.; MARTINS, F.S.; SANTOS, S.C.A. Microrganismos do solo envolvidos na degradação dos herbicidas clomazone e glifosate, em lavouras de arroz irrigado, no Rio Grande do Sul. In: II WORKSHOP SOBRE BIODEGRADAÇÃO, 2001, Campinas. Resumos... Campinas: Embrapa Meio Ambiente, 2001b. p.361-364.

9 MOGADATI, P.S.; LOUIS, J.B.; ROSEN, J.D. Determination of glyphosate and its metabolite, (aminomethyl) phosphonic acid, in river water. Journal of AOC International, v. 79, n.1, p.157-162, 1996.

10 MONSANTO. Herbicida Roundup. São Paulo, 1980. 10 p.

11 PRATA, F.; LAVORENTI, A.; REGITANO, J.B.; TORNISIELO, V.L. Transformação do Glifosato em LATOSSOLO VERMELHO sob plantio direto e convencional. In: CONGRESSO BRASILEIRO DE CIÊNCIA DO SOLO, 28., 2001, Londrina. Resumos... Londrina: Sociedade Brasileira de Ciência do Solo, 2001. p. 324.

10 RODRIGUES, B.N.; ALMEIDA, F.S. de. Guia de herbicidas. 3. ed. Londrina: IAPAR, 1995. 696 p. 